Title: Resource Sharing in the Digital Environment in India: Role of INFLIBNET

J ournal: Library Hi Tech News incorporating Online and CD Notes

Year: 2003 Volume: 20 Number: 3

Publisher: Emerald

\title{
Feature
}

\section{Resource Sharing in the Digital Environment in India: Role of INFLIBNET}

\author{
V.S. Cholin, J.K. Vijayakumar and T.A.V. Murthy \\ Introduction
}

Academic libraries are committed to providing and making accessible the best possible resources to serve the academic and research community. The libraries' most important technological goal is to give all citizens access to information regardless of format and provision of the information. The secondary goal is to make that access available from anywhere an authenticated user is situated. Networking is an essential process in this exercise as it facilitates access to vast information services. Networks have potential to improve library services in several ways. The continuous improvement in the networking technology helps libraries to reduce the cost of information provision, thus creating new opportunities for the libraries in providing information to its end users. In recent years libraries worldwide have been affected by an uncertain financial environment in which resource buying and licensing have been restricted, causing them to look at ways of extending their purchasing and access capabilities to compensate for reduced budgets. Cooperation and sharing of the resources is the need of the day in a digital environment.

Libraries and Information Centres are increasingly being called upon to provide more relevant, up-to-date and timely information to a wide range of users. To satisfy the varied needs they require connectivity and sophisticated networking to access a variety of information resources and formats, including digital full-text, sound, graphics, images, multimedia and hypertext. The University Grants Commission (UGC), the funding agency for universities in India, has been funding the universities through INFLIBNET Centre, to automate library functions and network the resources available in these libraries.

\section{INFLIBNET}

The Information and Library Network Centre (INFLIBNET), a major programme of the University Grants Commission (UGC) initiated in 1991, is committed to the modernization of libraries and information centres, and the establishment of a mechanism for information transfer and access, to support scholarship, learning and academic pursuits. It is also aimed at establishing a national network of libraries and information centres in universities, institutions of higher learning and R\&D institutions in India. It is basically a national co-operative endeavour in resource development, sharing and utilization. INFLIBNET Centre functions through its Governing Council (GC), Governing Board (GB) and Finance Committee (FC). The membership of these three bodies is drawn, in addition to ex officio members from UGC, AICTE, CSIR, ICSSR, IUCs, from Vice-Chancellors, Directors, library information professionals, information technology experts and other professionals. The GC is headed by the Chairperson, UGC Governing Board, who is an eminent academician and researcher. 
Over the years, the programme has progressed steadily and since May 1996 it has become an independent autonomous Inter-University Centre under UGC to co-ordinate and implement a nation-wide high-speed data network using state-of-the-art technologies for connecting all the university libraries in the country. INFLIBNET has become a major player in promoting scholarly communication among academicians and researchers in India.

\section{Objectives and functions of INFLIBNET}

Envisaged in the Memorandum of Association are:

- To promote and establish communication facilities to improve capability in information transfer and access, that provide support to scholarship, learning, research and academic pursuit through cooperation and involvement of agencies concerned.

- To establish the computer communication network, "INFLIBNET", to link libraries and information centres in universities, institutions deemed to be universities, colleges, UGC information centres, institutions of national importance and R\&D institutions, etc. with attempts to avoid duplication of effort.

On an experimental basis the digitization of theses database is being addressed. An attempt is being made to provide the table of contents of the selected titles from six libraries and provide access to full text journals from these libraries by enhancing the resource base. This service is being initiated with few libraries on an experimental basis via consortia arrangement.

\section{Where INFLIBNET stands today - activities}

INFLIBNET has been in operation for a decade. It is developing and expanding in size, resources and services, and has some significant results that are visible and noteworthy. This progress has been possible only due to the continuous support of the parent body, UGC, and the participating libraries. Some of the significant results are:

- Financial support to the tune of Rs 6.5 lakhs each to 142 university libraries for the purpose of automation and networking; the purchase of computers, software; site preparation; network development and connectivity using telephone lines and Internet Service Providers (ISPs).

- So far more than 75 percent of the libraries have become operational to utilize the recurring grant (provided for the first five years to maintain the computer system, support data entry for retro-conversion, and cover the costs of consumables including the telephone charges to sustain and develop these automation activities.

- A grant of Rs 1 lakh each to 65 libraries to establish core facilities and connectivity to the network for accessing the information available on the Internet and other libraries.

- The existing staff working in these libraries was called upon at INFLIBNET to provide the intensive training on the use of IT. The Centre has conducted 20 such training courses to help the operational staff of these libraries to implement the IT in their libraries. The one-week workshops were also conducted similarly for the executives working for the libraries who were trained at INFLIBNET. Seven such workshops have been conducted covering more than 150 executives. Apart from this, onsite training has been provided at more than 35 places.

- INFLIBNET has been providing regional level training to help the librarians from the college libraries to automate their library functions using the library management software developed by the Centre. It has conducted more than 30 such programs, training more than 600 professionals in the last year. These courses are conducted in collaboration with the university library/Department of Library and Information Science. These courses 
will help the college librarians to implement the SOUL Software in their libraries and automate all the library functions.

- Software for University Libraries (SOUL) - the state-of-the-art library management software designed and developed at INFLIBNET - has been well accepted by the academic community and has been installed at more than 100 libraries and many universities and institutions have placed orders for it to be installed soon.

- Union databases have been developed to provide access to the Library holdings. The Union database contains serials, theses, books, experts, projects, etc., and is being updated constantly and is available online for access at www.inflibnet.ac.in User-friendly search engines have been developed to provide access to such database content.

- INFLIBNET has initiated two new major projects: the Retrospective Conversion collection of five major libraries; and Document Delivery Service from six major libraries.

- The provision for technical guidance to all the libraries for implementation of IT.

- Implementation of the MARC-21 interface to SOUL software as well as the reverse interface.

- Various kinds of information retrieval services such as CD-ROM-based collections, access to OCLC FirstSearch, Table of Contents page service, etc.

- INFLIBNET hosts an annual convention to provide a platform for librarians and IT professionals in the form of CALIBER, which has become an important forum to discuss the modern trends in library technology applications. This event has become an international conference and will have held its first such event, CALIBER-2003, at Ahmedabad with the theme, "Mapping Technology in Libraries and People" February 1315, 2003 (see www.inflibnet.ac.in/calibers/caliber03.html).

More importantly, INFLIBNET has been able to create an IT-conscious environment in university libraries. Librarians have now accepted and are eagerly working to bring these changes in their libraries.

\section{Consortia initiatives at INFLIBNET}

Universities in India are finding it hard to maintain the subscriptions even to core journals, due to increasing costs shrinking library budgets and price escalation against major currencies. On average, an Indian university library subscribes to even less than 500 journals and at many universities there are no subscriptions. In comparison, in major university libraries in more developed countries the average number of journal titles subscribed to can exceed 10,000. Interestingly, the collective titles subscribed to by the Indian university libraries seem to be more than 5,000 scholarly journals. This suggests that there is a workable model for resource sharing to bridge the collections gap. Second, there is a need for increasing the access to scholarly journals, not being subscribed to by any of these libraries due to budget restrictions.

It appears that the whole world is moving towards greater rates of electronic publication and the cost of electronic publishing may be cheaper than that of the print version. Academic users can increasingly hope to have access to their learned journal articles in electronic form. Forming a consortium of libraries has become one solution to maximise a resource base: Initiative has been taken in this direction by the leadership of six Vice Chancellors and the librarians to explore how to serve users better with a consortia approach. INFLIBNET will play a major role in enhancing access to the collection of one library to the group of libraries. This approach will address both expanded access to resources among the libraries and also the possibility for greater resources available on consortia purchase or license from publishers, aggregators, and non-profit organizations. Several proposals and pricing modules were discussed and six libraries willing to come together with assistance from INFLIBNET established a consortium on an experimental basis, which will improve overall resource sharing among members. 
UGC has taken initiative to provide the electronic access to major journals for all the university libraries. The UGC NET, which is in the process of being established, will play a major role in providing electronic access to this e-journals collection, reflecting disciplines in the Life Sciences, Physics, Chemistry and Mathematical Sciences.

\section{Going digital}

A digital library (DL) does not exist without content, and the nature and extent of the content dictates the DL's ability to encourage knowledge creation. DLs are important because they encourage the type of e-content resources that help preserve a nation's literary and cultural heritage, record the work of the nation's scholars in science and literature and drive knowledge creation through individual effort and collaborative processes. Creating e-content can be timeconsuming and expensive and in many nations this process is a result of a combination of commercial and non-commercial entities creating bibliographic, multimedia, textual and statistical databases. DLs have been defined in many ways; however, it is important to acknowledge their important role as e-media managers. Therefore, a DL should be regarded as a deliberately assembled collection of electronic documents stored in widely distributed databases and made available to a large, geographically unspecific audience through a portal or other software device that provides intellectual access to and possibly the capability to react to the entire collection. Electronic documents may be in a wide variety of formats including naturallanguage text documents, statistical tables, financial data, and multimedia clippings or files.

\section{Content creation in India}

Convergence of print medium, databases and telecommunications has led to the advent of the electronic content industry. The content industry has come to mean various commercial and noncommercial activities relating to the bibliographic, textual and statistical databases as well as the information, education and entertainment materials in electronic form including audio, video and multimedia forms. The Government of India is giving priority to promoting this human-resourceintensive industry extensively in the country.

\section{Problems}

Developing nations like India face many problems in content creation. The distribution of cultural materials in various geographic locations throughout the nation is problematic. The problem of unavailability of the organizational means to share records can be resolved by building a union catalogue that could be accessible in digital or analog formats. Many institutions do not have the program or the resources for long-term preservation, especially in the e-media environment. Problems, such as the lack of knowledge about the value of digital documentation and preservation of the rich cultural heritage and resources including the art, literature, historical records and monuments of the nation; lack of policies and programs that support this type of documentation and preservation; lack of initiatives that support and disseminate the research and development about preservation of intellectual outputs are all barriers to content creation. The Indian language-based systems are crucial for the growth of the content creation and for spreading the impact of IT to the grass-roots level. All Government-funded software tools, developed for handling information in Indian languages, will be actively promoted for widespread use and made available at a nominal cost.

\section{INFLIBNET's role}

In India, a strong move to digitize the internal sources of libraries in universities and other academic institutions has yet to take place. These sources contain rich, precious and unique sources of information which are hidden, even unlocked, like theses and dissertations. As a starting-point it is proposed to digitize the theses collection in Indian university libraries. The theses submitted to universities in requirement of the $\mathrm{PhD}$ degree are difficult to access, as they are stocked only in the university library at the institution where the student studied. In contrast with this, the idea of eTheses and Dissertations (ETD) is becoming more common world-wide with standards, and where the document can be easily located, readily accessible and delivered over the Web. In India also, most researchers already write their theses in electronic format using 
standard word-processing, desktop publishing and graphics software. Changing the means for submitting theses from paper to electronic format will result in a more efficient and less costly process for the researcher in terms of the cost and time involved in making multiple paper-bound copies. INFLIBNET online theses database already contains sufficient search fields and a search engine has been developed to access this database. Fulltext of theses can be hosted in individual universities so that a federated search can be developed, or hosted on the INFLIBNET Web site for wider access.

In much the same way, the digitization of manuscripts available in Indian university libraries will be made available in the near future. Access to externally developed digital contents through consortia mode to all participating libraries is already initiated through OCLC and some other international and national vendors. Training for existing manpower in digital technologies will also be provided by INFLIBNET. Resource sharing through networks is the basic objective of our document delivery service.

\section{Conclusion}

India is known for its rich and diverse cultural heritage. It also possesses a vast wealth of traditional knowledge. This is mostly in Indian languages and should be promoted and preserved for posterity. The Government will therefore take initiatives, through appropriate projects, to create electronic images of the information on the Indian arts and culture, for wider dissemination and research. As per IT policy, the Government of India will encourage and promote Indian companies and organizations to host their contents only on Web servers located in India with Indian domain addresses and these will be made available at internationally competitive prices. Here, INFLIBNET, as the nodal agency established for improving libraries in India, will be playing an important role in creating digital libraries.

\section{Suggested Reading}

Chand, P. and Kumbar, T.S. (1999), "Online access to union databases developed at INFLIBNET", Papers Presented at XXII All India Conference of IASLIC, Agra, pp. 65-72

Cholin, V.S. and Karisiddappa, C.R. (2002a), "Library consortia for academic libraries in the epublishing era", paper presented during the CALIBER-2002, Jaipur, 14-16 February.

Cholin, V.S. and Karisiddappa, C.R. (2002b), "Consortia approach for academic libraries: emerging solution for optimum utilization of resources", paper presented at the SIS-2002 Conference, Mangalore University, Mangalore, 27-29 May.

Cholin, V.S. and Murthy, T.A.V. (2002), "Sharing of resources among university libraries through consortia: INFLIBNET approach", paper presented at the SIS-2002 Conference held at Mangalore University, Mangalore, 27-29 May.

Hosamini, H.G. and Cholin, V.S. (2001), "INFLIBNET and its role in computerization of libraries in India", in Moorthy, A.L. and Reddy, M.S. (Eds), Papers Presented at First South Indian Library Conference, Hyderabad, 18-19 October.

INFLIBNET Web site: available at: www.inflibnet.ac.in

Kumar, P. and Kumbar, T.S. (2000), "Networked information services and resource sharing: the INFLIBNET approach", in Vengan, R., Mohan, H.R. and Raghavan, K.S. (Eds), Information Services in a Networked Environment in India. Papers Presented at the 7th National Convention for Automation of Libraries in Education and Research Institutes (CALIBER-2000), Chennai, India, 16-18 February, INFLIBNET Centre, Ahmedabad, pp. 1.46-1.55.

Kumbar, T.S., Cholin, V.S. and Prakash, K. (2000), "Development of union databases at INFLIBNET and role of university libraries", in Vengan, R., Mohan, H.R. and Raghavan, K.S. (Eds), Information Services in a Networked Environment in India. Papers Presented at the 7th National Convention for Automation of Libraries in Education and Research Institutes (CALIBER-2000), Chennai, India, 16-18 February, INFLIBNET Centre, Ahmedabad, pp. 3.423.49 . 
Murthy, T.A.V. and Cholin, V.S. (2002), "Role of INFLIBNET in modernization and networking of libraries in India", invited paper presented during one-day National Round-Table Meeting on Modernization and Networking of Libraries in India organized by the Ministry of Culture, Government of India, 5 January.

Vijayakumar, J.K. and Murthy, T.A.V. (2001), "Need of a digital library for Indian theses and dissertations: a model on a par with the ETD initiatives at international level", in Urs, S.R., Rajashekhar, T.B. and Raghavan, K.S. (Eds), Digital Libraries: Conference Papers of the 4th International Conference of Asian Digital Libraries (ICADL-2001), Bangalore, India, 10-12 December, pp. 384-90.

Vijayakumar, J.K. and Sreekumar, M.G. (2001), "Consortia approach among the higher education and research libraries in India: a dire need of the hour", Proceedings of National Seminar on Library Co-operation in a Networked World, University of Calicut, Kozhikode, India, 25-26 May, Ess Ess, New Delhi, pp. 58-74.

\section{V.S. Cholin}

(cholin@inflibnet.ac.in) is Scientist,

\section{J.K. Vijayakumar}

(vijay@inflibnet.ac.in) is Science and Technology Officer,

and

\section{T.A.V. Murthy}

(tav@inflibnet.ac.in) is Director, INFLIBNET Centre in Ahmedabad, India. 